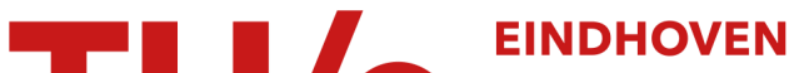

\section{Composition profiling of GaAs/AIGaAs quantum dots grown by droplet epitaxy}

\section{Citation for published version (APA):}

Bocquel, J., Giddings, A. D., Mano, T., Prosa, T. J., Larson, D. J., \& Koenraad, P. M. (2014). Composition profiling of GaAs/AIGaAs quantum dots grown by droplet epitaxy. Applied Physics Letters, 105, 153102-1/4. [153102]. https://doi.org/10.1063/1.4897006

DOI:

$10.1063 / 1.4897006$

Document status and date:

Published: 01/01/2014

\section{Document Version:}

Publisher's PDF, also known as Version of Record (includes final page, issue and volume numbers)

\section{Please check the document version of this publication:}

- A submitted manuscript is the version of the article upon submission and before peer-review. There can be important differences between the submitted version and the official published version of record. People interested in the research are advised to contact the author for the final version of the publication, or visit the DOI to the publisher's website.

- The final author version and the galley proof are versions of the publication after peer review.

- The final published version features the final layout of the paper including the volume, issue and page numbers.

Link to publication

\section{General rights}

Copyright and moral rights for the publications made accessible in the public portal are retained by the authors and/or other copyright owners and it is a condition of accessing publications that users recognise and abide by the legal requirements associated with these rights.

- Users may download and print one copy of any publication from the public portal for the purpose of private study or research.

- You may not further distribute the material or use it for any profit-making activity or commercial gain

- You may freely distribute the URL identifying the publication in the public portal.

If the publication is distributed under the terms of Article $25 \mathrm{fa}$ of the Dutch Copyright Act, indicated by the "Taverne" license above, please follow below link for the End User Agreement:

www.tue.nl/taverne

Take down policy

If you believe that this document breaches copyright please contact us at:

openaccess@tue.nl

providing details and we will investigate your claim. 


\title{
Composition profiling of GaAs/AIGaAs quantum dots grown by droplet epitaxy
}

\author{
J. Bocquel, ${ }^{1}$ A. D. Giddings, ${ }^{2}$ T. Mano, ${ }^{3}$ T. J. Prosa, ${ }^{2}$ D. J. Larson,${ }^{2}$ and P. M. Koenraad ${ }^{1}$ \\ ${ }^{1}$ Department of Applied Physics, Eindhoven University of Technology, P.O. Box 513, 5600 MB Eindhoven, \\ The Netherlands \\ ${ }^{2}$ CAMECA Instruments, Inc., 5500 Nobel Drive, Madison, Wisconsin 53711, USA \\ ${ }^{3}$ National Institute for Materials Science, 1-2-1 Sengen, Tsukuba, Ibaraki 305-0047, Japan
}

(Received 29 July 2014; accepted 22 September 2014; published online 13 October 2014)

\begin{abstract}
Droplet epitaxy (DE) is a growth method which can create III-V quantum dots (QDs) whose optoelectronic properties can be accurately controlled through the crystallisation conditions. In this work, GaAs/AlGaAs DE-QDs have been analyzed with the complimentary techniques of crosssectional scanning tunneling microscopy and atom probe tomography. Structural details and a quantitative chemical analysis of QDs of different sizes are obtained. Most QDs were found to be pure GaAs, while a small proportion exhibited high intermixing caused by a local etching process. Large QDs with a high aspect ratio were observed to have an Al-rich crown above the GaAs QD. This structure is attributed to differences in mobility of the cations during the capping phase of the DE growth. (C) 2014 AIP Publishing LLC. [http://dx.doi.org/10.1063/1.4897006]
\end{abstract}

Solid-state quantum dots (QDs) are nanostructures which have attracted strong interest for a number of technologies such as light-emitting diodes, lasers, and solar cells. With dimensions on the order of tens of nm, excitons are spatially confined within a QD; the resultant quantum mechanical properties are determined by their morphology such as the size, shape, or composition. Traditionally QDs are grown using the Stranski-Krastanov growth mode, which takes advantage of the lattice mismatch present between different materials in a heterostructure. ${ }^{1}$ The morphology of the QDs obtained by this process is defined by strain relaxation and surface energetics. Consequently, an abrupt change of the QD morphology from one shape to another is observed, for example, from a pyramid to a dome. ${ }^{2}$ More recently, another approach to the fabrication of QDs has been developed, the so-called droplet epitaxy (DE) method. ${ }^{3}$ This technique is based on the crystallisation of a metallic group-III droplet under a flux of elements from group-V. It has been demonstrated that thermally activated, kinetically driven mass transport processes play a major role in $\mathrm{DE}^{4}$ As a result, the geometrical profile of these DE-QDs can be tuned continuously and accurately by adjusting only the crystallisation conditions. ${ }^{5}$

While the DE growth technique can be applied to most III-V semiconductors systems, strain free GaAs/AlGaAs heterostructures offer a particular advantage by having a strong relation between their morphology and optoelectronic properties. In particular, the systematic study of GaAs/AlGaAs DE nanostructures as a function of various growth parameters has improved understanding of the kinetics of the crystallisation of the material which diffuses out of the initial Ga droplet. $^{6}$ Knowledge about the crystallisation process and the effect of capping on the structural properties remains limited due to the lack of in-situ characterisation techniques. Using atomic-scale microscopy, in this paper, we present insights into the structural and chemical analysis of GaAs/ AlGaAs DE-QDs. The QD chemical composition, size, and shape, in addition to being a principle factor which control the final optoelectronic properties of a $\mathrm{QD}$, also reflect the crystallisation process during the QD creation. To this end, cross-sectional scanning tunneling microscopy (X-STM) and atom probe tomography $(\mathrm{APT})^{7}$ measurements have been performed.

A single multilayer sample composed of four GaAs/ AlGaAs QD layers was grown on a GaAs (001) substrate by $\mathrm{DE}$ in a molecular beam epitaxy system. These four layers each have different initial volumes of Ga deposited to form the metallic droplets. Following the growth of an initial $100 \mathrm{~nm} \mathrm{Al}_{0.33} \mathrm{Ga}_{0.66} \mathrm{As}$ buffer layer, DE was performed a procedure which consists of (i) Ga droplet formation, (ii) crystallization into GaAs, and (iii) capping by AlGaAs. The Ga droplets were deposited using a supply of Ga without As flux (background As pressure less than $1 \times 10^{-7} \mathrm{~Pa}$ ). The Ga droplets were created by depositing either $1.5,2,3$, or 5 monolayers (ML) of $\mathrm{Ga}$ at $200{ }^{\circ} \mathrm{C}$ in the respective layers. The crystallization was performed under a supply of $\mathrm{As}_{4}$ with a beam equivalent pressure of $0.033 \mathrm{~Pa}$ at $200^{\circ} \mathrm{C}$. In order to produce highly luminescent QDs, an uncapped annealing at $400{ }^{\circ} \mathrm{C}$ is performed in-situ after the crystallisation of each QD layer. ${ }^{8}$ Additionally, a post-growth rapid thermal annealing (RTA) at $750{ }^{\circ} \mathrm{C}$ for $4 \mathrm{~min}$ is performed in-situ after the completion of the full structure. ${ }^{9,10}$ As a result, the capped QDs investigated in these experiments are in their final, functional state.

The capped QDs were investigated by X-STM performed at room temperature under UHV conditions $\left(7 \times 10^{-9} \mathrm{~Pa}\right)$. Prior to measurement, the specimen was thinned by mechanical polishing to a thickness of approximately $0.12 \mathrm{~mm}$. It was then cleaved in-situ in the STM presenting a clean and atomically flat (110) or (11) surface for analysis. Electrochemically etched W tips were used as probes. The STM was operated with an applied voltage bias of $-2.5 \mathrm{~V}$ at $50 \mathrm{pA}$ in constant current mode.

The specimens for APT measurement were prepared using standard dual-beam focused ion beam techniques. The $400 \mathrm{~nm}$ GaAs buffer layer on top of the AlGaAs region of 
interest meant that an additional protective cap, other than an ion-beam deposited Pt layer, was not necessary for processing. The orientation of the lifted-out lamella relative to the crystalline axes of the wafer was tracked during the lift-out process. APT data were acquired using a CAMECA LEAP $4000 \mathrm{X}$ with a straight flight path of length of $90 \mathrm{~mm}$. The sample temperature was $50 \mathrm{~K}$. Field evaporation of ions was initiated with the assistance of a $355 \mathrm{~nm}$ laser, which pulsed with a frequency of $250 \mathrm{kHz}$. Each pulse had a duration of about $10 \mathrm{ps}$ and delivered an energy of $1 \mathrm{pJ}$. The specimen voltage was adjusted so that, on average, for every 1000 laser pulses, three ions would be detected. With these conditions, the measured group-III to group-V element ratio was found to be close to stoichiometry, with As accounting for $49 \%$ of the detected ions.

The structures observed by X-STM and APT can be described as comprising of three principle regions: (i) the AlGaAs matrix, (ii) the Ga-rich QDs, and (iii) Al-rich (Gadepleted) crowns, see Fig. 1(d). The structure of QDs and the Al-rich crowns will be considered separately.
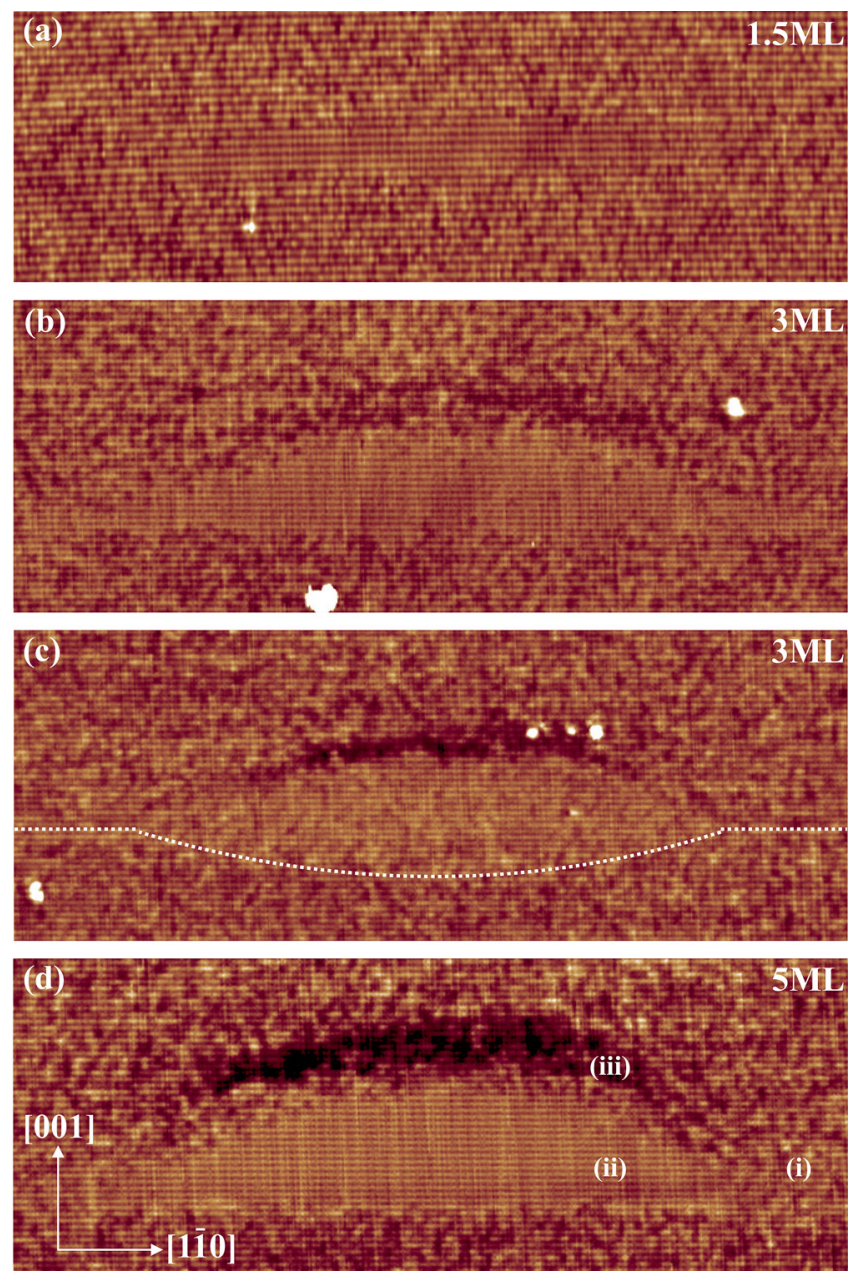

FIG. 1. X-STM filled states topography images of DE-QDs. Under the $\mathrm{X}$-STM imaging conditions, $\mathrm{Al}$ atoms give dark local electronic contrast compared to the Ga atoms. (a) $17 \mathrm{~nm} \times 56 \mathrm{~nm}$ image of a DE-QD grown with 1.5 ML of deposited Ga. (b) Low and (c) high level of Al intermixing in $32 \mathrm{~nm} \times 76 \mathrm{~nm}$ images of DE-QDs grown under the exact same conditions with $3 \mathrm{ML}$ of deposited Ga. The dotted line indicates roughly the bottom interface of the QD. (d) $32 \mathrm{~nm} \times 76 \mathrm{~nm}$ image of a DE-QD grown from 5 ML of deposited Ga. Labeled are (i) the AlGaAs matrix, (ii) the Ga-rich QD, and (iii) Al-rich (Ga-depleted) crown.
The geometrical profile of the GaAs/AlGaAs DE-QDs varies continuously as a function of the growth parameters. Increasing the volume of Ga deposited for the formation of metallic droplets results in QDs with higher aspect (heightto-base length) ratio. This smooth evolution of the morphology is made possible by the stepped nature of their sidefacets which are typically considered to be abrupt.

About $90 \%$ of the GaAs/AlGaAs DE-QDs exhibit a low level of $\mathrm{Al}$ intermixing as shown in the STM topography images in Figs. 1(a), 1(b), and 1(d). Under the X-STM imaging conditions, $\mathrm{Al}$ atoms give dark local electronic contrast compared to the $\mathrm{Ga}$ atoms as can be seen in the $\mathrm{Al}_{x=0.33} \mathrm{Ga}_{1-x} \mathrm{As}$ matrix. Because the GaAs/AlGaAs system is strain-free, the $\mathrm{Al}$ concentration inside each GaAs QD could not be estimated by the strain relaxation method otherwise used for most strained III-V heterostructures. ${ }^{11}$ Instead, as in a previous study, ${ }^{12}$ the fraction of $\mathrm{Al}$ atoms in the QDs can be estimated by counting the atoms in the surface layer directly on the X-STM image. This method found that the Al fraction, $x$, could have values between 0.0 and 0.1 , varying from one QD to the other.

However, this counting method is limited by the fact that each atom must be individually resolved. Above a concentration of $x \sim 0.2$, the disorder becomes too great and the contrast becomes too low to make an accurate estimate. As a result, the $\mathrm{Al}$ fraction in the $\mathrm{AlGaAs}$ matrix cannot be determined by X-STM. In contrast, compositional measurements by APT find that $x=0.31 \pm 0.02$, in agreement with the expected value of $x=0.33$ from growth calibrations.

APT data of a QD grown from $3 \mathrm{ML}$ of Ga provide a quantitative, spatially resolved chemical analysis of the specimen. Figure 2(a) shows a side view (left) and a top view (right) of a single QD by means of isosurfaces indicating the (A-grey) Al fraction $x=0.55$ and (B-yellow) Ga fraction $1-x=0.9$. The morphology of the QD is clearly defined by isosurface B. The elongation along the [1실 axis and the anisotropy previously revealed by the scanning probe techniques are clearly visible. The chemical composition of the QD can be determined from a composition profile along the [001] growth direction shown in Fig. 3. In agreement with the X-STM data, APT finds the QD core to be pure GaAs.

A low level of intermixing is observed at most of the QD interfaces in either the X-STM or APT data. This low level of intermixing is consistent with the small interdiffusion coefficient between GaAs and $\mathrm{AlGaAs}$ reported for annealing temperatures of up to $750^{\circ} \mathrm{C}$ (Ref. 13) as were used for our sample. The inter-diffusion might, however, be slightly enhanced ${ }^{14}$ for structures like our QDs that are grown at low temperature, due to the creation of point defects, like vacancies, that will mediate the diffusion of cations. ${ }^{15}$ Because the inter-diffusion is spatially limited to the QD interfaces, the pure GaAs core composition of large QDs is not affected.

In the STM images, the bottom interface of these DEQDs is generally more broadened than the upper facets, and, as reported in a earlier study, ${ }^{12}$ local GaAs intrusions are often present beneath. The depth of these intrusions clearly ranges from one bilayer $(0.56 \mathrm{~nm})$ to a few nanometers and are non-homogeneously distributed in the plane. In the STM data, a full spatial correlation was found between the 
(a)
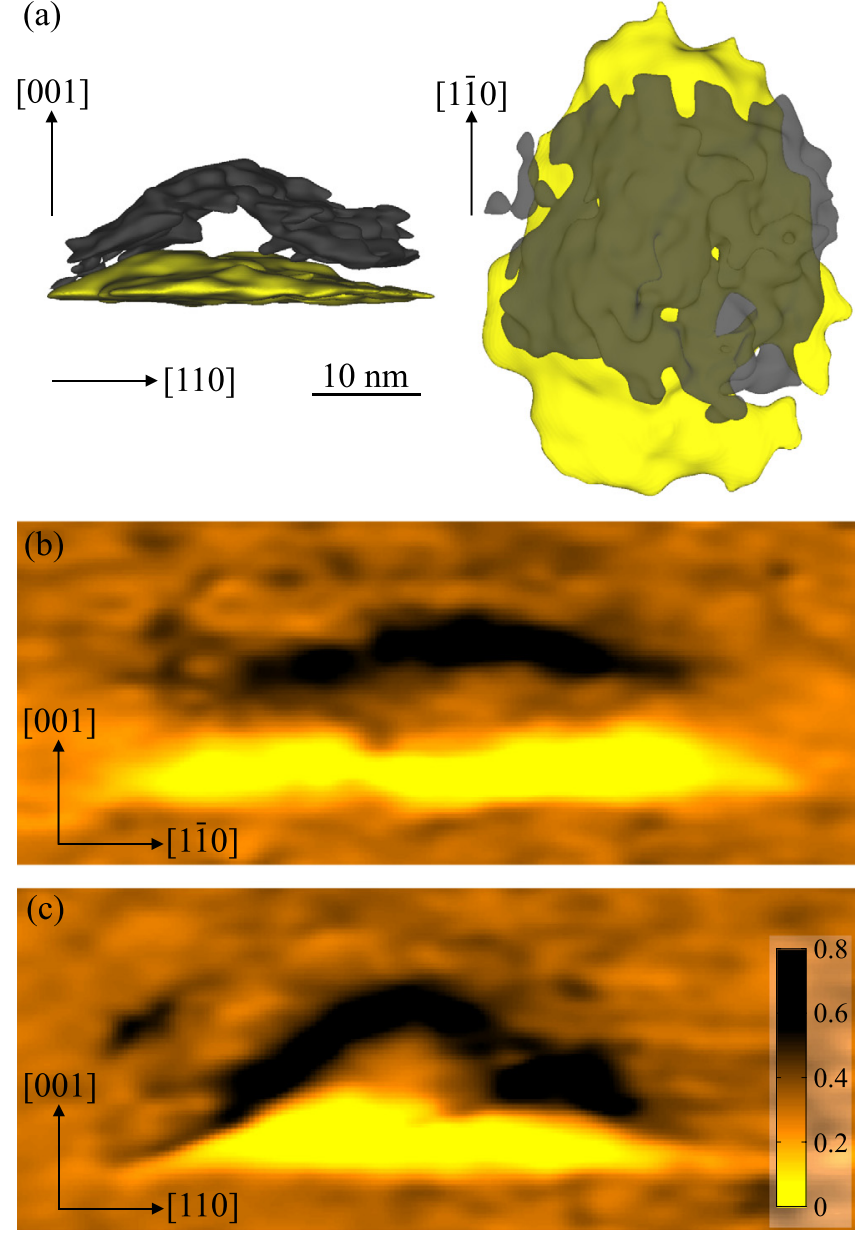

FIG. 2. (a) Side (left) and top (right) views of a single QD measured by APT. Isosurfaces contain volumes where $\mathrm{Al}$ fraction $x \geq 0.55$ (grey) and $\mathrm{Ga}$ fraction $1-x \geq 0.9$ (yellow). The $10 \mathrm{~nm}$ scale bar applies to both views. (b) and (c) 2D concentration profiles of a $60 \mathrm{~nm} \times 30 \mathrm{~nm}$ area sampled with a $2 \mathrm{~nm}$ depth show the $\mathrm{Al}$ fraction, $x$, through the $\mathrm{QD}$ along the two orthogonal directions. The color scale goes from $\mathrm{Al}$ fraction $x<0.15$ (yellow) to $x>0.7$ (black).

presence of an intrusion and the presence of $\mathrm{Al}$ in the otherwise pure GaAs QD. All the strongly intermixed QDs, like the one in Fig. 1(c), show intrusion into the underlying epilayer. The presence of intrusions below the position of the metallic droplet has been reported in systems where, like in

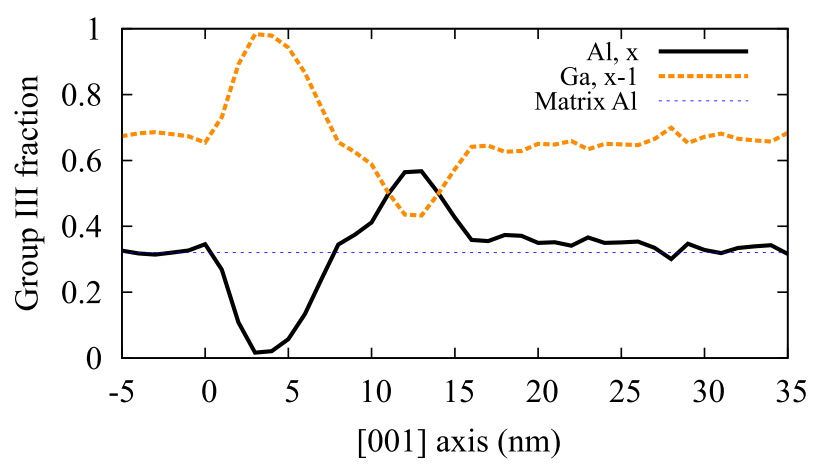

FIG. 3. 1D composition profile of a QD obtained from the APT data. The profile was created using a $15 \mathrm{~nm}$ diameter cylinder positioned to intersect with the centre of the QD. The cylinder was aligned in the [001] growth direction and sampled in $1 \mathrm{~nm}$ bins. The relative compositions of $\mathrm{Al}$ and $\mathrm{Ga}$ are shown, along with the bulk composition of a volume of $\mathrm{Al}_{x} \mathrm{Ga}_{1-x} \mathrm{As}$ matrix located between the QD layers.
DE, a liquid metallic droplet (In, Ga) is formed on an arsenide semiconductor surface. ${ }^{16}$ Hence, several models have been developed which account for this so-called "drilling" or "etching" effect. ${ }^{17}$ The mechanisms suggested for this drilling effect partially explains the diversity of the nanostructures obtained by DE. ${ }^{18,19}$

Whilst most of the DE-QDs present a low degree of $\mathrm{Al}$ intermixing, a small number of QDs $(\sim 10 \%)$ were observed to contain a very high concentration of $\mathrm{Al}$, as shown in Fig. 1(c). By visual inspection, the $\mathrm{Al}$ fraction of these QDs is less than the matrix $(x=0.3)$, but is higher than the X-STM counting limit of $x<0.2$. Due to their scarcity, none of these types of QDs were imaged in the APT measurements. These highly intermixed QDs all have a high aspect ratio and there is no pure $\mathrm{GaAs}$ region; that is, $\mathrm{Al}$ is distributed throughout the QD. Another recurring peculiarity of these highly intermixed QDs is the shifted position of their bottom interface, which is found up to a few nanometers below the nominal position as indicated by the white dotted line in Fig. 1(c).

Similarly to the mechanism for the small GaAs intrusions, a drilling effect is held responsible for both the shifted interface and the high concentration of $\mathrm{Al}$ in these large QDs. The main process driving the etching is the dissolution of As atoms from the substrate and their diffusion into the metal droplet. As a result, an As concentration gradient forms inside the metal droplet. In the system presented here, the As atoms diffuse towards the liquid/vapor interface, after which they either escape in the vacuum or lead to crystallisation into GaAs at the interface. This results in the liquefaction of the substrate locally below the Ga droplet. This local etching of the substrate starts with the formation of the $\mathrm{Ga}$ droplet and proceeds until it is completely consumed. For this reason, a low As background favors the drilling. ${ }^{20}$ If the environment stays completely As free, the final structure is a hole inside the substrate surrounded by a GaAs ring. If the droplet is rapidly subjected to a high As flux, which occurs in the DE process, the As gradient is reduced. The metal droplet turns into a shallower GaAs QD with relatively small GaAs intrusions in the substrate.

This model explains well why large intrusions and a strong $\mathrm{Al}$ intermixing are more frequently found for the largest QDs grown from 5 and $3 \mathrm{ML}$ of deposited Ga. At constant As flux, the crystallisation of large droplets requires a longer time, leading to a stronger etching of the surface. Additionally, the As gradient, which is the driving force, is strongest in QDs with higher aspect ratios. As a result, the substrate is heavily etched below the whole QD and the diffusion of $\mathrm{Al}$ in the QD is hereby strongly promoted. Considering that $\mathrm{Al}$ is present throughout these types of QDs, the diffusion must have taken place before the complete crystallisation of the liquid droplet.

An Al-rich (Ga-depleted) crown is another structural feature associated with the GaAs/AlGaAs DE-QDs which is revealed by X-STM and APT analysis, presented in Figs. 1 and 2. The color scale of the APT derived 2D concentration maps in Figs. 2(b) and 2(c) goes from Al fraction $x<0.15$ (yellow) to $x>0.7$ (black). This local Al enrichment is found above 70\% of the larger QDs (grown from 3 and $5 \mathrm{ML}$ of Ga drops). Very rarely (less than 5\% of cases), QDs grown from $2 \mathrm{ML}$ of Ga deposited show such a feature. QDs grown from 
1.5 ML of Ga do not exhibit any local Al enrichment. As clearly displayed in Figs. 1 and 2(a), only the upper part of the QD is covered by this crown. Moreover, the 3D and 2D APT representations of the QD shows that the shape of this Al-rich region shape is anisotropic. The crown has a chevron (inverted-v) shape along the major axis of the QD. The magnitude of this enrichment in $\mathrm{Al}$ above the QD can be estimated quantitatively from the composition profile along the [001] growth direction shown in Fig. 3 and by measuring the bulk composition inside the isosurface shown in Fig. 2(a). The average $\mathrm{Al}$ fraction is $x=0.67$ inside the $x \geq 0.55$ isosurface.

A mechanism based on the difference in $\mathrm{Ga}$ and $\mathrm{Al}$ adatom mobility is suggested to explain the enrichment of $\mathrm{Al}$ (depletion of Ga) above high aspect ratio QDs. The thermodynamically stable configuration of GaAs on AlGaAs is a 2D layer due to the high solid-solid surface tension and the lack of strain. However, the high aspect ratio of the QD nanostructures increases the surface tension at the apex and confers a curvature to the growth front right on top of the QDs. This geometrical condition results in the diffusion of $\mathrm{Al}$ and $\mathrm{Ga}$ adatoms along the side facets during capping. Because $\mathrm{Ga}$ atoms are more mobile than $\mathrm{Al}$ atoms, ${ }^{21} \mathrm{Ga}$ atoms will be more likely to diffuse away from QD top, while, comparatively, the $\mathrm{Al}$ atoms will not travel as far. In this way, the AlGaAs layer crystallised on top of the QD remains rich in $\mathrm{Al}$.

Additionally, the difference in migration may also vary depending on the side facets. This mechanism explains well the highly localized position of this feature at the top of the QDs and its anisotropy. Furthermore, because this separation process continues until the growth front has flattened out, the Ga-depleted regions extend notably along the [001] direction, leading to the observed residual Al-enrichment above the crown. Additional crystallisation kinetics undeniably should play a role in the local Ga depletion of the AlGaAs capping layer.

A number of structural details and the chemical analysis of GaAs/AlGaAs DE-QDs have been presented in this study. The QDs are found to be almost pure GaAs. GaAs intrusions were also found below a number of the QDs and attributed to local etching processes. This process was found to be responsible for major drilling and Al-intermixing for the largest QDs. An Al-rich capping of the high aspect ratio QDs was observed, which is attributed to the difference in mobility between cations. The fabrication of GaAs/AlGaAs QDs by $\mathrm{DE}$ is subject to phenomena altering the final dimensions and chemical composition of the QDs. GaAs DE-QDs have heights of several $\mathrm{nm}$ and diameters of several tens of $\mathrm{nm}$, hence, the quantum confinement is the strongest along the growth direction. The fluctuations of several $\mathrm{nm}$ in QD height arising from the etching mechanism undoubtedly compromise the final goal of controlling the optical emission of these DE-QDs. A high concentration of $\mathrm{Al}$ is known to favor the presence of structural defects in AlGaAs. The observed Al-rich crown is therefore expected to be detrimental to the optical emission. Preventing those phenomena is essential for keeping the control over the QD morphology that can be obtained by fine tuning growth parameters. From the presented investigations, the key factors are the kinetics of the crystallization which is dominated by the size of the Ga droplet and the resulting surface tensions. The formation of the Al-rich crown can thus be avoided by engineering the capping layer to flatten and control the height of the QDs.

${ }^{1}$ J. Stangl, V. Holy, and G. Bauer, Rev. Mod. Phys. 76, 725 (2004).

${ }^{2}$ G. Costantini, A. Rastelli, C. Manzano, P. Acosta-Diaz, G. Katsaros, R. Songmuang, O. G. Schmidt, H. V. Känel, and K. Kern, J. Cryst. Growth 278, 38 (2005).

${ }^{3}$ N. Koguchi, J. Vac. Sci. Technol. B 11, 787 (1993).

${ }^{4}$ S. Sanguinetti and N. Koguchi, Molecular Beam Epitaxy: From Research to Mass Production (Elsevier, 2013), pp. 95-111.

${ }^{5}$ J. Bocquel, S. Bietti, J. Keizer, T. Mano, P. M. Koenraad, and S. Sanguinetti, "Precise Shape Control in GaAs/AlGaAs Droplet Epitaxy Quantum dots" (unpublished).

${ }^{6}$ S. Bietti, C. Somaschini, and S. Sanguinetti, Nanotechnology 24, 205603 (2013).

${ }^{7}$ T. F. Kelly and M. K. Miller, Rev. Sci. Instrum. 78, 031101 (2007).

${ }^{8}$ T. Mano, M. Abbarchi, T. Kuroda, C. A. Mastrandrea, A. Vinattieri, S. Sanguinetti, K. Sakoda, and M. Gurioli, Nanotechnology 20, 395601 (2009).

${ }^{9}$ T. Mano, T. Kuroda, K. Mitsuishi, M. Yamagiwa, X.-J. Guo, K. Furuya, K. Sakoda, and N. Koguchi, J. Cryst. Growth 301, 740 (2007).

${ }^{10}$ S. Sanguinetti, T. Mano, A. Gerosa, C. Somaschini, S. Bietti, N. Koguchi, E. Grilli, M. Guzzi, M. Gurioli, and M. Abbarchi, J. Appl. Phys. 104, 113519 (2008).

${ }^{11}$ P. Offermans, P. M. Koenraad, J. H. Wolter, K. Pierz, M. Roy, and P. Maksym, Phys. Rev. B 72, 165332 (2005).

${ }^{12}$ J. G. Keizer, J. Bocquel, P. M. Koenraad, T. Mano, T. Noda, and K. Sakoda, Appl. Phys. Lett. 96, 062101 (2010).

${ }^{13}$ T. E. Schlesinger and T. Kuech, Appl. Phys. Lett. 49, 519 (1986).

${ }^{14}$ S. Sanguinetti, K. Watanabe, T. Kuroda, F. Minami, Y. Gotoh, and N. Koguchi, J. Cryst. Growth 242, 321 (2002).

${ }^{15}$ J. Moison, C. Guille, F. Houzay, F. Barthe, and M. Van Rompay, Phys. Rev. B: Condens. Matter 40, 6149 (1989).

${ }^{16}$ Z. M. Wang, B. L. Liang, K. A. Sablon, and G. J. Salamo, Appl. Phys. Lett. 90, 113120 (2007).

${ }^{17}$ C. Heyn, A. Stemmann, and W. Hansen, Appl. Phys. Lett. 95, 173110 (2009).

${ }^{18}$ Z. M. Wang, K. Holmes, J. L. Shultz, and G. J. Salamo, Phys. Status Solidi A 202, R85 (2005).

${ }^{19}$ A. Stemmann, C. Heyn, T. Koppen, T. Kipp, and W. Hansen, Appl. Phys. Lett. 93, 123108 (2008).

${ }^{20}$ C. Heyn, Phys. Rev. B 83, 165302 (2011).

${ }^{21}$ K. Ohta, T. Kojima, and T. Nakagawa, J. Cryst. Growth 95, 71 (1989). 